\title{
Do People Favour Policies that Protect Future Generations? Evidence from a British Survey of Adults
}

\author{
HILARY GRAHAM*, J. MARTIN BLAND**, RICHARD COOKSON***, \\ MONA KANAAN ${ }^{* * * *}$ AND PIRAN C. L. WHITE***** \\ * Department of Health Sciences, University of York, York, YO10 5DD, United Kingdom \\ e-mail: hilary.graham@york.ac.uk \\ ** Department of Health Sciences, University of York, York, YO10 5DD, United Kingdom \\ e-mail: martin.bland@york.ac.uk \\ *** Centre for Health Economics, University of York, York, YO10 5DD, United Kingdom \\ e-mail: richard.cookson@york.ac.uk \\ **** Department of Health Sciences, University of York, York, YO10 5DD, United Kingdom \\ e-mail: mona.kanaan@york.ac.uk \\ ***** Environment Department, University of York, University of York, York, YO10 5NG, United \\ Kingdom \\ e-mail: piran.white@york.ac.uk
}

\begin{abstract}
Long-range temporal choices are built into contemporary policy-making, with policy decisions having consequences that play out across generations. Decisions are made on behalf of the public who are assumed to give much greater weight to their welfare than to the welfare of future generations. The paper investigates this assumption. It briefly discusses evidence from sociological and economic studies before reporting the findings of a British survey of people's intergenerational time preferences based on a representative sample of nearly 10,00o respondents. Questions focused on two sets of policies: (i) health policies to save lives and (ii) environmental policies to protect against floods that would severely damage homes, businesses and other infrastructure. For both sets of policies, participants were offered a choice of three policy options, each bringing greater or lesser benefits to their, their children's and their grandchildren's generations. For both saving lives and protecting against floods, only a minority selected the policy that most benefited their generation; the majority selected policies bringing equal or greater benefits to future generations. Our study raises questions about a core assumption of standard economic evaluation, pointing instead to concern for future generations as a value that many people hold in common.
\end{abstract}

\section{Introduction}

Policy making involves decisions that play out over time. Policies to improve welfare systems and protect the environment require upfront investment to secure longer-term benefits; deciding against such policies may leave current generations relatively unscathed but hit future generations hard. The fact that policies have inter-temporal impacts (impacts that vary over time) has long 
been recognised, with publicly-funded services - education, health care, social protection - contributing to a wider flow of resources across generations (Levell et al., 2015). Policy making is based on the assumption that the public give much greater weight to their welfare than to the welfare of future generations (Stern et al., 2006; HM Treasury, 2013). Yet there is scant empirical evidence on people's preferences regarding the timing of benefits and costs across generations with respect to health and environmental policies. We focus on these intergenerational time preferences.

Changes in the Earth's environment and climate are putting the issue of intergenerational impacts into sharp relief (Myers and Patz, 2009; Pretty, 2013). Pre-industrial societies, with their limited technologies and low fossilfuel consumption, have modest temporal impacts; their economic systems and lifestyles do little to alter environmental conditions for future generations. However, industrialising and post-industrial societies rest on systems of production and consumption that are 'producing futures... the innovative use of the earth's resources ushered in the industrial revolution, but it has taken until now for people to recognise the long-term consequences of these practices' (Adams and Groves, 2007: xiv). Economic growth and health gains for their populations have been sustained at the cost of risks and hazards that fall forward in time - and fall on future generations in particular (IPCC, 2014). As the Brundtland Commission on the Environment and Development noted three decades ago, modern societies 'borrow environmental capital from future generations with no intention or prospect of repaying [it]' (UN, 1987: 8).

The consequences of this mining of environmental capital are captured in widely used measures of planetary conditions, including fossil-fuel emissions, global temperatures, ocean acidification and the loss of tropical forests and biodiversity (Rockström et al., 2009; Steffen et al., 2006). These key environmental indicators point to a gradual deterioration in planetary conditions from the $1850 \mathrm{O}$ and an accelerating pace of decline from the 1950s as high-income countries, and more recently China and other emerging economies, 'have been mortgaging the health of future generations to realise economic and development gains in the present' (Whitmee et al., 2015: 1).

Future generations include distant people living many centuries from now - and the children and grandchildren of adults living today. Take, for example, global average temperature (global average land and ocean temperature), the most widely-used indicator of human disturbance to the stable environmental systems that have enabled societies to flourish over the last 10,000 years (Steffen et al., 2011). The burning of fossil fuels to provide energy for industries, households and transport drove up global temperatures by over $1^{\circ} \mathrm{C}$ between 1880 and 2015 (IPCC, 2014; WMO, 2016), with most of this increase confined to the last 50 years (IPCC, 2014). Because concentrations of long-lived greenhouse gases are continuing to rise (WMO, 2016), the international threshold of a maximum 
increase of $2^{\circ} \mathrm{C}$ to avoid dangerous ${ }^{1}$ climate change is set to be breached by 2050 . Based on today's life expectancies (over 70 years as a global average and over 80 in high-income countries), most people alive today can expect to be alive in 2050 (WHO, 2015). Without decisive action by today's governments, estimates suggest that global temperatures will rise by at least $4^{\circ} \mathrm{C}$ by 2100 (IPCC, 2014; New et al., 2011; Watts et al., 2015), a timeframe approaching the anticipated life expectancy of children born in high-income countries today. For example, children born in Japan, Australia, Spain and Singapore in 2017 could expect to be alive in 2100, as could girls born in northern and western Europe, Canada and New Zealand (WHO, 2015).

As this example makes clear, when governmental leaders make decisions affecting future conditions, they are shaping a future that will rapidly become 'the present of others' (Adams and Groves, 2007: 13). Questions about the moral status of future generations are therefore an unavoidable dimension of policy making. Key among these questions is how to value their wellbeing. One answer is to work from the principle of moral equality: everyone has the same moral worth and everyone's life and life prospects matter equally (Kymlicka, 2002). Decisions made in line with this principle would not treat people differently simply because they are differently located in time. As the Stern report on the economics of climate change argued, the welfare of future generations should be treated 'on a par with our own' (Stern et al., 2006: 31). However, as many observers have noted, contemporary policy making does not adhere to this principle. Instead, it privileges the welfare of current over future generations (Adams and Groves, 2007; Stern et al., 2006). Both the economics and the politics of policy making contribute to this generational bias.

With respect to the economics of policy making, the standard approach to economic evaluation is to convert anticipated benefits and costs, both now and in future years, into a common metric, typically its present monetary value, and to give less weight to future costs and benefits than to current ones (HM Treasury, 2013). To do this, a time weight ('a discount rate') is applied when assessing the value of different policy options. As is widely recognised, discounting builds intergenerational inequity into the policy appraisal process. It means that dividends yielded by policies in 30 years' time are accorded very low value from the perspective of the present; even if declining rather than constant discount rates are used for longer time periods, the present values of such policies dwindle to almost nothing. In consequence, it is policies with near-term benefits and deferred costs that are seen to provide the greatest overall benefit to society.

Discounting has evolved in response to the complexities of evaluating policy impacts over variable timescales, including the market return that the investment would otherwise secure, the expectation that future societies will be richer than those today and a catastrophic risk premium to take account of the possibility of 
the collapse of societies and their human populations (Oliver, 2013). Discounting is also seen to take account of public preferences. It is based on the principle that individuals, and society as a whole, 'prefer to receive goods and services now rather than later and to defer costs to future generations' (HM Treasury, 2013: 26).

The politics of policy making is seen to reinforce this 'bias in favour of present over future generations' (Thompson, 2010). The short electoral cycles on which democratic governments operate compress policy horizons, with governments preferring policies where benefits can be demonstrated within their period of office (Thompson, 2010). Additionally, democratic governments are expected to represent those who voted them into power. Because children, like those yet to be born, have no direct political voice, what therefore matters for future generations is the relative weight that today's citizens place on their wellbeing.

Our paper examines this issue through a study that allows direct comparisons between intergenerational time preferences for health and environmental policies. Our study was based on commissioned questions in a continuous national survey of British adults. We asked participants about their preferences for health policies to save lives and then, in subsequent months of the survey, environmental policies to protect against disastrous floods causing severe damage to industries, homes and other infrastructure. In both policy examples, participants were asked to select one of three options, each with a different distribution of benefits across 'your generation', 'your children's generation' and 'your grandchildren's generation'. We determine whether participants preferred policies that brought greater benefit to their generation compared to future generations and whether these preferences differed between the two policy examples. We also note whether social factors (age, gender, parental status, socioeconomic status, health status) increased the odds of preferring a policy that maximised the benefits to the current generation. The paper concludes by reflecting on the findings and what they suggest about the value that people place on the welfare of future generations.

\section{Evidence on people's concern for future generations}

Evidence on people's concern for the welfare of future generations is spread across a range of research fields which have developed largely independently of each other. Two sources of evidence are considered here: sociological studies of family relationships and economic studies of individuals' time preferences. Sociological studies highlight the importance of 'the interchange between generations' (Giddens, 1991: 146) in grounding people's identities and structuring their lives, including key life transitions (e.g. child to adult) and life events (birth, death). Economic studies are built around a more decontextualised conception of the individual, and one focused around self-interest and rational decision-making. 
Not surprisingly, the two approaches provide contrasting perspectives on the weight that people place on the welfare of future citizens.

Family studies focus on people's relational identities and the everyday practices that reproduce these relationships over time (Morgan, 1996). Studies point in particular to emotional and material commitments that cross generations (Arber and Timonen, 2012). Even in high-income societies where birth rates are low and where women are less likely to have children, intergenerational ties are the norm. In these societies, around a fifth of the population is under 18 years, the large majority of adults are parents and the majority of those aged 60 and over are grandparents (Leopold and Skopek, 2015; OECD, 2011; US Census Bureau, 2015). Generational ties extend across decades: in Britain for example, the next generation is being born to mothers whose mean age is 30 (ONS, 2013) and almost all young children have at least one living grandparent (Hawkes and Joshi, 2007).

Demographic changes, evident first in high-income countries and now a global pattern, are seen to be strengthening vertical family structures over horizontal ones. For example, the rise in life expectancy is enabling grandparents, parents and grandchildren to have 'longer years of shared lives', reaching an average of 35 years for grandmothers in the US (Leopold and Skopek, 2015). Changes in household structures, including the increase in lone motherhood, are further strengthening intergenerational ties, particularly ones between children, mothers and grandmothers (Silverstein et al., 1998). Bengston coined the term 'intergenerational solidarity' to describe relationships that cross generations, a concept that embraces affective commitments as well as the mutual sharing of time and material resources (Bengtson, 2001). Turning the spotlight on the timepersistent relationships that anchor people's lives, such evidence suggests that many adults care deeply about the welfare of future generations.

Economic studies suggest that this is, in fact, not the case. A key source of evidence comes from studies of people's time preferences (their preferences regarding the timing of benefits and costs) for saving lives (Cairns and van der Pol, 2000). The studies pose hypothetical and context-free questions about lifesaving programmes, presenting respondents with a choice between ones that will save lives now or in the future. Time frames can range from the relatively short term (e.g. 'now' vs '25 years from now') to the long term (e.g. 'now' vs '100 years from now') (Cropper et al., 1994; Johannesson and Johansson, 1996). A consistent finding is that individuals value lives saved now more highly than lives saved in the future. For example, the typical respondent in a US study of the general public regarded the life of one person saved today as equivalent to six lives saved in 25 years and 45 lives saved in 100 years' time (Cropper et al., 1994). The broad conclusion is therefore that 'the public values the lives of people in future generations much less than they value the lives of people in this generation' (Frederick, 2003: 39). Within this broad conclusion, studies have noted some 
social differences in people's time preferences, with participants who are older and in poorer health attaching less importance to saving lives in the future (e.g. Cairns and van der Pol, 2000; Johannesson and Johansson, 1996). In addition, for time horizons of 25 years or more, those with a child under the age of 18 at home have been found to have a stronger preference for programmes that save lives today (Cropper et al., 1994).

While their evidence suggests that people attach less priority to saving future lives, researchers have been careful to put caveats around this conclusion. They note how the study's design and elicitation methods can influence the findings (Cairns and van der Pol, 2000; Frederick et al., 2002). They note, too, that people are being asked about anonymous lives: the discrete choice questions about saving lives now or in the future typically give little or no information about whose lives will be saved (Chapman, 2001; Cropper et al., 1994; Johannesson and Johansson, 1996). It is acknowledged, too, that the extended timescales used in time preference studies - e.g. from now to 100 years - make it hard to disentangle people's intra-generational time preferences (preferences regarding the timing of benefits and costs accruing to oneself and across one's own life time) from their intergenerational time preferences (those accruing to future others and across generations) (Chapman, 2001). Intra- and intergenerational preferences may therefore be confounded (Frederick, 2003). For example, individuals may heavily discount their own futures (Lawless et al., 2013) and yet, at the same time and in line with the evidence from family studies, accord a high value to protecting the lives of future generations.

However, few time preference studies frame their questions in intergenerational terms. An exception is a US study (Frederick, 2003). Based on samples of registered voters and students, it asked participants to choose between two programmes to save 300 lives. The first programme would save all the lives 'in your generation' and none in either 'your children's generation' or 'your grandchildren's generation'; the second would save 100 lives in each of the three generations. When forced to choose between totally discounting future lives (programme 1) and complete intergenerational equity (programme 2), 80 per cent opted for the programme that secured equal benefits for all three generations. As this suggests, the public may, in line with the principle of moral equality, be opposed to giving less weight to lives simply because they will be lived in the future. As family studies suggest, they may not discount future impacts in ways or to the extent that standard economic approaches to policy appraisal assume. In other words, the bias against future generations built into the practice of discounting may not be in line with public preferences.

In this study, we investigated whether, as indicated by economic studies of time preferences, adults in Britain preferred policies that maximised the benefits for their generation or, in line with sociological evidence on intergenerational ties, they selected policies that gave equal or greater benefit to their children's and 
grandchildren's generations. To our knowledge, this is the first empirical study to compare economic and sociological perspectives in terms of people's preferences for health and environmental policies. We began by asking about health policies to save lives. We then selected an alternative policy field with a different policy outcome. Subsequent months of the survey asked about environmental policies to protect against flood damage to buildings and other infrastructure. The questions were developed iteratively, informed by the emerging findings and by guidance from our project advisory groups.

Our study was based on the Opinions and Lifestyle Survey (OLS), a survey of adults aged 16 and over (ONS, 2014). The survey is managed by the UK's Office of National Statistics (ONS), governed by the ONS code of practice and overseen by the National Statistician's Data Ethics Advisory Committee (UK Statistics Authority, 2009). Our study was approved by the University of York Department of Health Sciences Research Governance Committee.

The OLS uses a random probability sample of private households in Britain, drawn from the Postcode Address File, the most complete address database in the UK containing approximately $26 \mathrm{~m}$ addresses (ONS, 2014). The OLS sample is stratified by region and socio-demographic profile. For the socio-demographic stratification, the OLS survey team use three measures: the proportion of households with no car, the proportion of households where the household reference person has an occupation in a higher socioeconomic group and the proportion of people aged $>65$ years.

A new sample is drawn for each survey - which ran monthly until 2015, when the survey months were reduced from twelve to eight. One adult per household is randomly selected for a face-to-face Computer Assisted Personal Interview. The survey consists of socio-demographic questions (gender, age, socioeconomic status, health status etc.), together with commissioned questions. It achieves a response rate of 50-55 per cent and a monthly sample of around 1000 respondents; weights are provided to account for the sample design and non-response.

We commissioned a series of discrete choice time preference questions framed around policies to save lives and protect against disastrous floods across survey months in 2013 to 2015. The questions were asked immediately after the OLS's standard set of socio-demographic questions (ONS, 2014). We also commissioned a question on parental status that enabled identification of parents with adult children as well as those with current responsibility for a child/children under 16 years in the household.

Our first time preference question built on Frederick's study (Frederick, 2003) and focused on health policies to save lives. Run across July, August and September 2013, it included the option of choosing a policy that brought equal benefits to each generation (Figure 1, version 1). When we saw the pattern of preferences, we became concerned that the framing of the question may have introduced a possible 'equal shares' bias. Participants may have opted for the 


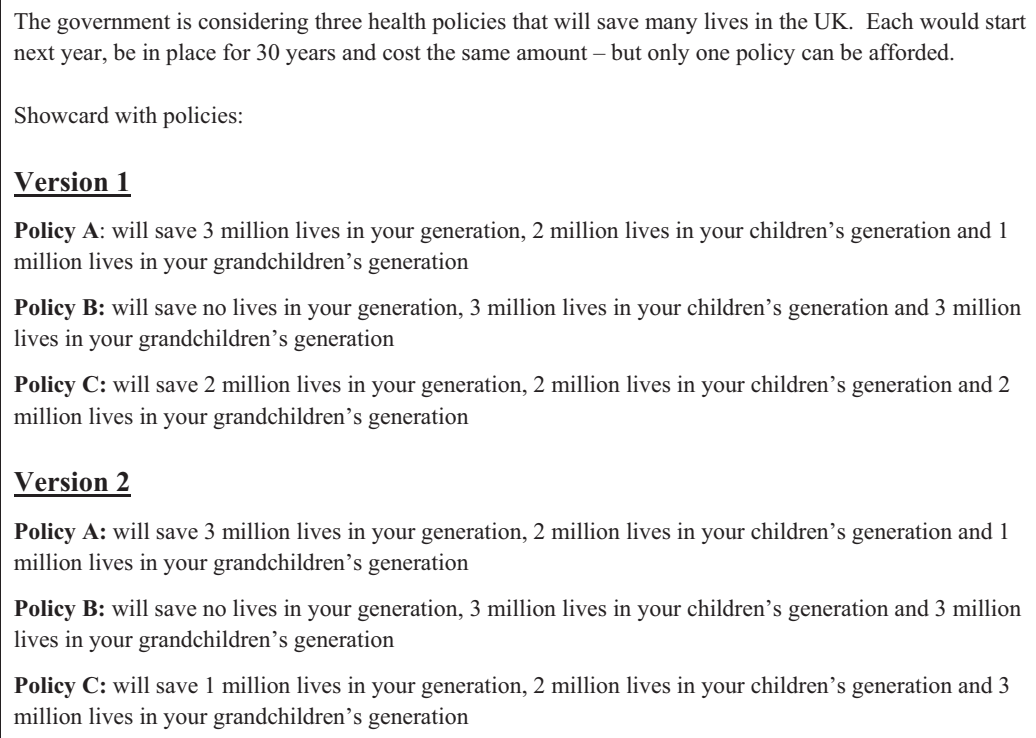

Which of the policies on this card would you prefer? Policy A Policy B Policy C

Plus (spontaneous only) no preference, require more information, don't know and refused to answer

Figure 1. Health policies to save lives

equal shares policy (Policy C) simply because it represented the equity position, with little consideration of the relative weight they attached to the lives of current and future generations. So, in further months of the survey (Dec 2013 and Jan 2014), we modified the question to remove this option ${ }^{2}$. Instead of a policy saving the same number of lives in each of the three generations, Policy $\mathrm{C}$ brought some benefits to their generation and progressively more to subsequent generations (Figure 1, version 2). In consequence, respondents had either to select the policy favouring their generation (Policy A) or one of two alternatives, both of which were strongly biased to future generations (Policy B and Policy C).

Like the first version of the policy question, this modified question again produced a pattern of responses that would not have been predicted by time preference studies. This raised a further question. Did a question framed around health policies to save children's and grandchildren's lives have an emotional loading that elicited a stronger future orientation than one framed around non-human benefits? In other words, were we investigating time preferences using a policy scenario where 'intergenerational solidarity' was most likely to be expressed? 

The UK government is considering three environmental policies to protect against disastrous floods causing
severe damage to homes, businesses, transport, communications and other infrastructure in the UK. Each
policy would start next year, be in place for 30 years and cost the same amount - but only one policy can be
afforded.

Showcard with policies:

\section{Version 1}

Policy A will result in 300 fewer disastrous floods in your generation, 200 fewer disastrous floods in your children's generation and 100 fewer disastrous floods in your grandchildren's generation

Policy B will result in no change in disastrous floods in your generation, 300 fewer disastrous floods in your children's generation and 300 fewer disastrous floods in your grandchildren's generation

Policy C will result in 200 fewer disastrous floods in your generation, 200 fewer disastrous floods in your children's generation and 200 fewer disastrous floods in your grandchildren's generation

\section{Version 2}

Policy A will result in 300 fewer disastrous floods in your generation, 200 fewer disastrous floods in your children's generation and 100 fewer disastrous floods in your grandchildren's generation

Policy B will result in no change in disastrous floods in your generation, 300 fewer disastrous floods in your children's generation and 300 fewer disastrous floods in your grandchildren's generation

Policy C will result in 100 fewer disastrous floods in your generation, 200 fewer disastrous floods in your children's generation and 300 fewer disastrous floods in your grandchildren's generation

Which of the policies on this card would you prefer? Policy A Policy B Policy C

Plus (spontaneous only) no preference, require more information, don't know and refused to answer

Figure 2. Environmental policies to protect against flood damage

We therefore chose an alternative policy field and framed the benefits in non-human terms. We asked a question about environmental policies to protect against flood damage to buildings and other infrastructure. The policy options were adapted from those asked about health policies and, like the saving lives questions, were run in two versions (Figure 2). The first version included the option of choosing a policy that brought equal benefit to each generation and was asked of respondents in the surveys run in February, March and May 2014 (Figure 2, version 1). The second version of the policy options replaced this option with one that brought progressively greater benefits across the three generations. It was included in the surveys run in October and November 2014 and January 2015 (Figure 2, version 2). Our questions were asked during and following months (the winter of 2013/2014) of exceptionally heavy rainfall and extensive flooding in Britain (Met Office, 2014).

A common format was used for both policies, with survey participants given a showcard and asked to select one of three policies which would start next year and be in place for 30 years (Figures 1 and 2). Spontaneous responses of no preference, require more information, don't know and refused to answer were also recorded. The choice order of the policies was varied each month. 
Our analysis focuses on participants who gave an answer to the policy question (i.e. stated either a policy preference or no policy preference). The latter group were included because, like those opting for Policy B or C, they did not follow economic predictions and select the policy that maximised the benefits to them. In presenting the results, we begin with descriptive statistics, looking first at overall preferences before considering their social patterning. We describe patterns by gender, age, highest educational qualification (degree or equivalent/other/none), health status (very good/good/fair, bad or very bad) and parental status (having parental responsibility for a child $<16$ years living in the household currently/in the past/never). With the exception of age, we provide weighted percentages for the policy choices; for age, mean age is used.

We then focus on the policy (Policy A) bringing most benefits to the generation to which participants belong (i.e. 'your generation'). We estimate the odds of choosing this policy against selecting another policy or indicating no policy preference, first in unadjusted and then adjusted models. We examine whether the odds of preferring Policy A vary by gender, responsibility for children, education etc. To do this, we take the category with the largest number of responses as our reference category: being female, having past responsibility for children, having educational qualifications below degree level and being in good health. This approach ensures that coefficients for these predictors have the smallest possible standard errors (Hosmer et al., 2013). With the reference category as the comparator, we then estimate the odds of choosing Policy A in the other groups (being male, having no or current responsibility for children etc.). Odds were calculated using logistic regression; 95 per cent confidence interval (CI) estimates were not weighted to account for sample design. However, as a check on the analyses, CI estimates accounting for the survey design were also computed, together with sensitivity analyses to account for the order of the policy question on the showcard and for potential clustering of responses by month. All analyses were conducted using STATA, version 13 (StataCorp, 2013).

\section{Results}

The large majority of participants were able and willing to express a view on the policy options, either by selecting one of the three policies or by stating that they did not have a preference. This group represents 95 per cent of those asked about policies to save lives $(n=2949$ and 1924 respectively for versions 1 and 2 of the policy question) and 93 per cent of those asked about policies to protect against floods ( $n=3055$ and 3081 for versions 1 and 2 of the policy question). Only a small proportion refused to answer ( $\leq 1$ per cent for all variants of the question), needed more information ( $\leq 5$ per cent) or did not know how to answer the question ( $\leq 1$ per cent). 
1. Saving lives

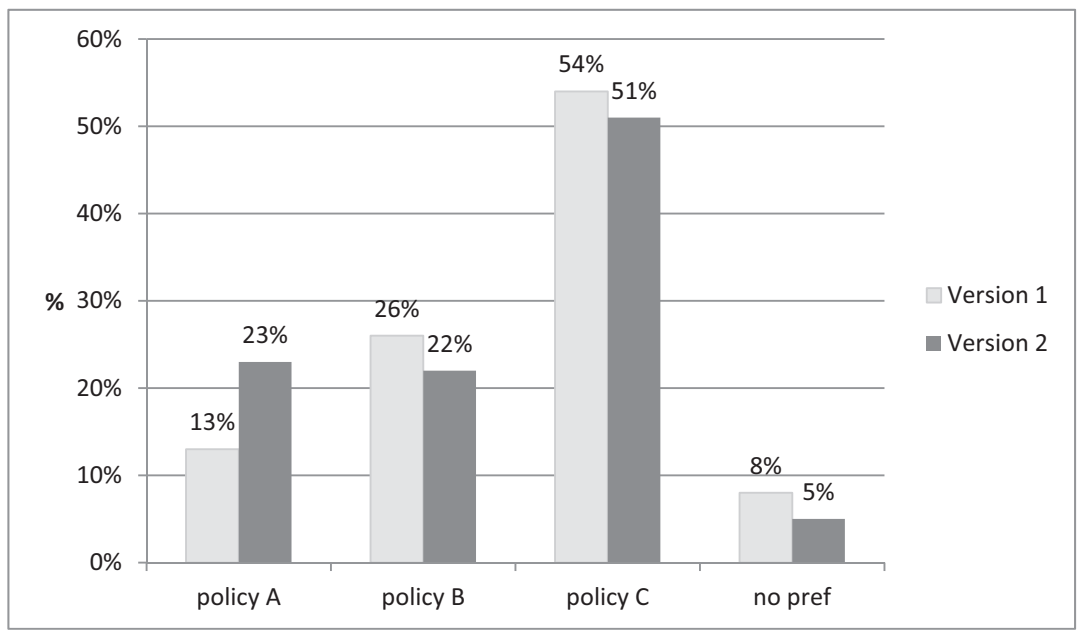

2. Protecting against floods

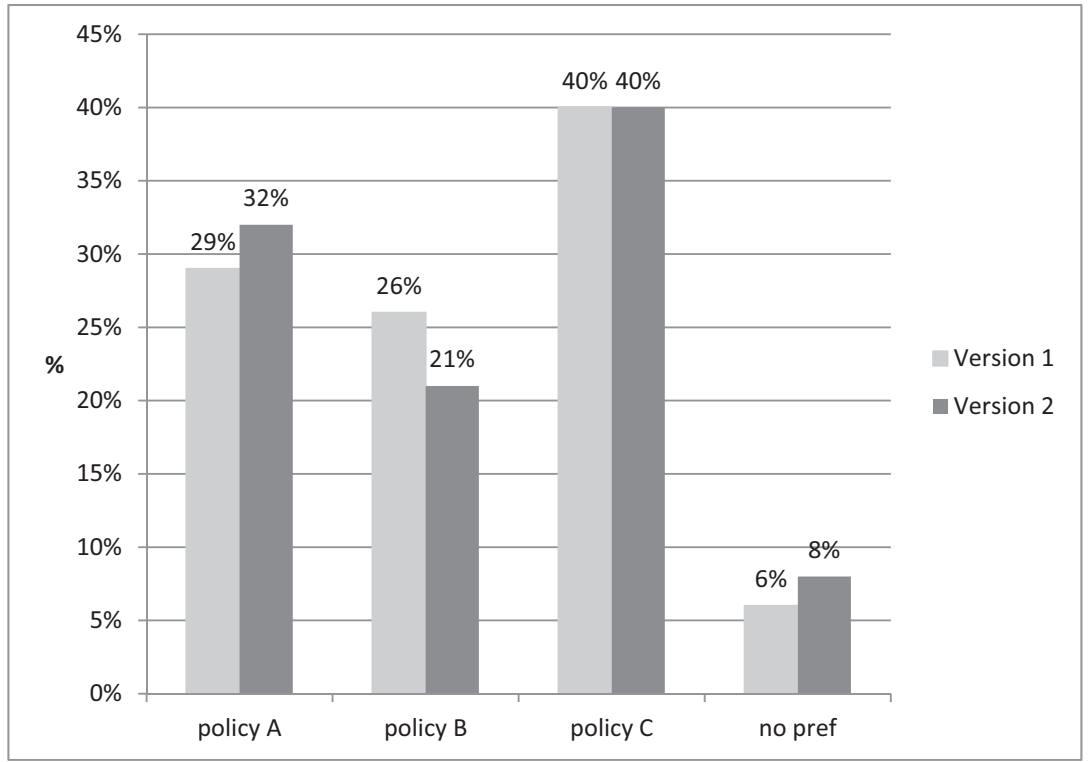

Figure 3. Policy preferences for saving lives and protecting against disastrous floods (weighted $\% s)$

\section{Overall policy preferences for saving lives and protecting against floods}

Figure 3 summarises the policy preferences for saving lives and for flood protection. For both policy scenarios and in both sets of policy options, only 
a minority of respondents preferred the policy that most advantaged their own generation (Policy A). The bias towards future generations was more marked for saving lives than protecting against disastrous floods. Less than one in four respondents opted for the policy that prioritised saving lives today over saving lives in the future; the proportion selecting Policy A was particularly low (13 per cent) when the policy choices included an equal shares option. The proportion of respondents opting to maximise benefits to their generation (Policy A) was higher when the policy options were framed around flood protection, at around three in ten. Nonetheless, twice as many respondents selected policies that clearly favoured future generations (i.e. Policies B and C).

Across both health and environmental policies and for both versions of the policy question, the most frequently selected policy was Policy C. Again this pattern was more pronounced when the policy outcome was lives saved. As Figure 3 indicates, it was the choice of the majority (over 50 per cent) who expressed a view on their policy preferences. When environmental policies were the focus, the proportion opting for Policy $\mathrm{C}$ was lower (at 40 per cent); however, it remained the most popular choice. Changing Policy $\mathrm{C}$ from one bringing equal benefits to the three generations (version 1) to one bringing progressively greater benefits to future generations (version 2) was associated with little variation in the proportion preferring this policy; the proportion fell from 54 per cent to 51 per cent for saving lives and remained unchanged at 40 per cent for protecting against disastrous floods.

Across both health and environmental policies, and in both versions of the policy question, a sizeable minority selected the policy (Policy B) from which they would derive no direct benefit and, instead, all the benefits would be enjoyed by future generations. For both saving lives and protecting against disastrous floods, this policy option was preferred by over one in five respondents; for version 1 of the policy questions, the proportion rose to one in four (Figure 3 ).

\section{Policy preferences: socio-demographic patterns}

Table 1 summarises the pattern of policy choices for saving lives and protecting against floods by gender, age, parental status, educational qualifications and health status. In no social group did Policy A represent the preference of the majority. For saving lives, Policy $\mathrm{C}$ was the most popular choice across all the dimensions of social position. The pattern was similar for protecting against disastrous floods but with two exceptions. As Table 1 indicates, among parents with children over the age of 16 and those with no educational qualifications, Policy A was the most frequently selected option.

Table 2 focuses on Policy A and presents the unadjusted and adjusted odds of choosing Policy A over the other policy responses (Policy B, Policy C, no policy preference). In the adjusted model and consistent with other time preference 
TABLE 1. Policy preferences in Britain for (i) saving lives (2013/2014) (ii) flood protection (2014/2015)

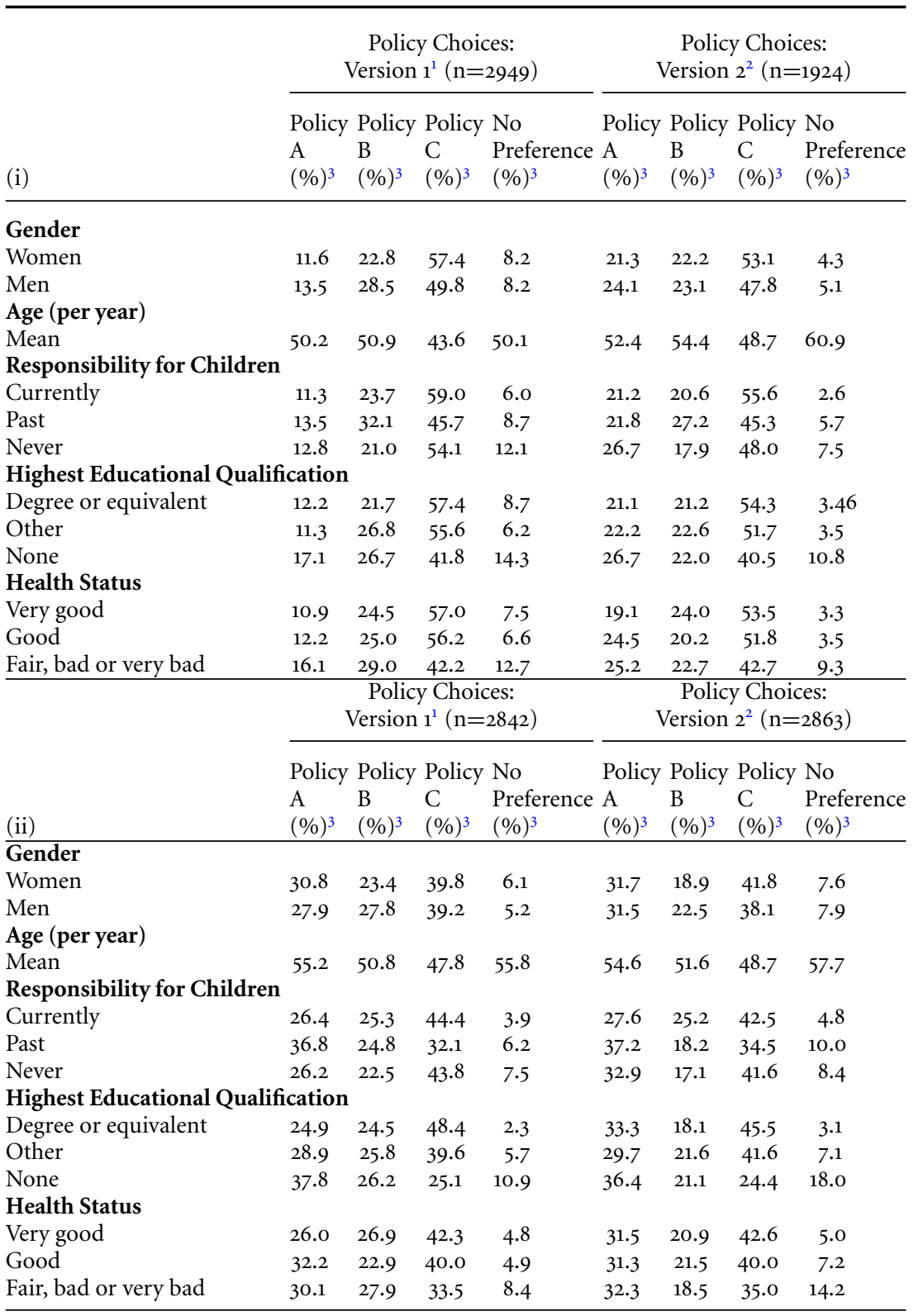

${ }^{1}$ has an 'equal shares' option

${ }^{2}$ does not have an 'equal shares' option

${ }^{3}$ weighted percentage, except for age 
TABLE 2(i). Saving lives: logistic regression analysis estimates for choosing Policy A versus the other policies or citing no preference, for versions 1 and 2 of the question. Unadjusted and adjusted Odds Ratios (OR) and 95\% Confidence Intervals (CI). Unweighted

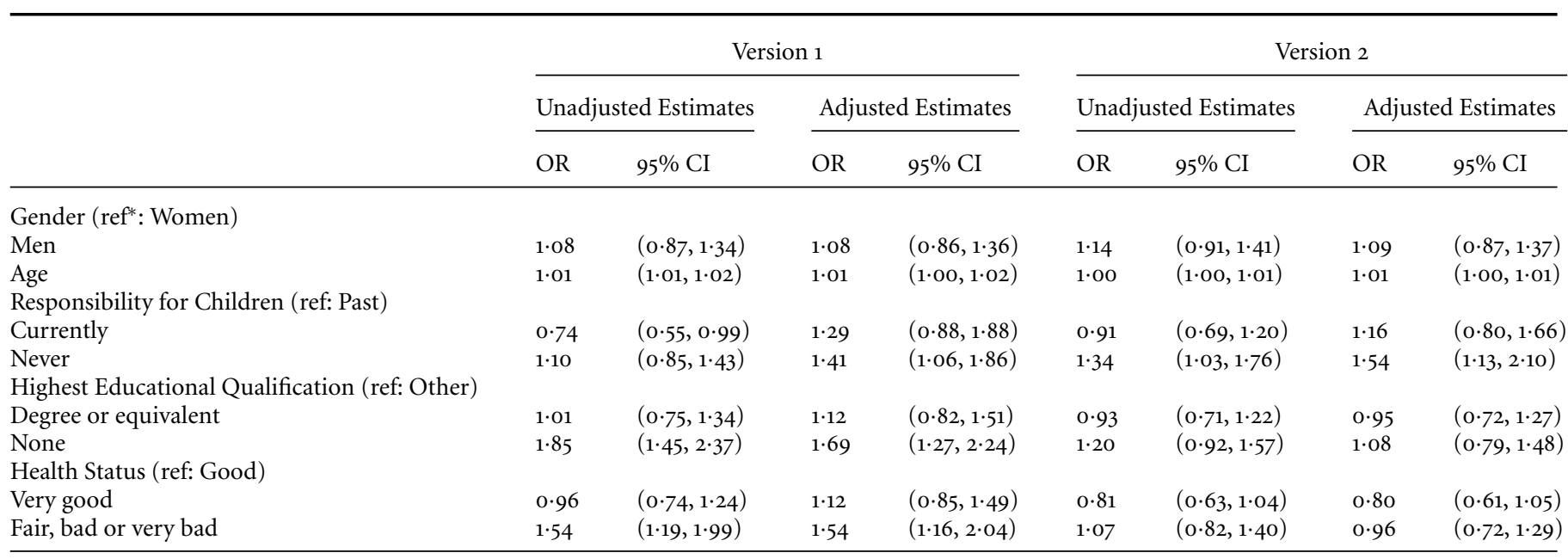

*ref: represents reference group. Reference groups are those with highest frequency. 
studies, age was a predictor of preferring Policy A; the odds increased with each additional year of age for both saving lives and protecting against floods. This pattern was evident across all versions of the policy question.

For policies to save lives, but not to protect against floods, parental status was an additional predictor. The odds of preferring Policy A were higher for those who had never been parents than for those who had current or past responsibility for children, a pattern different to that found in Cropper's US study (Cropper et al., 1994). When the policy options for saving lives included an equal shares option for Policy C (version 1 of the question), two further factors affected the odds of selecting Policy A: health status and educational status. In line with time preference studies, the odds of preferring the policy that favoured the current generation were greater for those in poor health. Thus compared to those in good health, for those in poor health (fair, bad or very bad) the odds of preferring Policy A were increased by a factor of 1.54 . Social disadvantage, as measured by having no educational qualifications, also increased the likelihood of preferring Policy A; the odds of a respondent with no educational qualifications preferring Policy A were 1.69 greater than a respondent in the reference category (with educational qualifications below degree level).

We examined whether the order in which the policy options were listed made a difference to the results as well as potential clustering of policy choices by month. Accounting for these factors produced results similar to those presented in Tables 2 (i) and 2 (ii). Taking account of survey weights also left the results substantially unchanged.

\section{Discussion}

Evidence from economic studies suggests that adults privilege their welfare over the welfare of future citizens (Oliver, 2013; HM Treasury, 2013). The consistent finding is that, when presented with hypothetical choices, individuals prefer programmes that bring benefits immediately and to their generation over ones bringing benefits in the future and to future generations. When aggregated, such individual responses suggest limited public support for policies to protect future generations. Such views are seen to be consistent with standard economic approaches which, whether based on constant or declining (hyperbolic) discount rates, value later benefits and costs less highly than earlier ones (Oliver, 2013; HM Treasury, 2013). They suggest that the public supports policies that contribute to 'the disenfranchisement of future generations' (Broome, 1994: 152).

However, evidence from family studies paints a different picture of the value that people place on the welfare of future generations. The studies document how commitments to what are perceived to be the interests of future generations play a structuring role in people's lives and contribute to the strong emotional and material bonds that extend across multiple generations. The evidence from 
TABLE 2(ii). Flood protection: logistic regression analysis estimates for choosing Policy A versus the other policies or citing no preference, for versions 1 and 2 of the question. Unadjusted and adjusted Odds Ratios (OR) and 95\% Confidence Intervals (CI). Unweighted

\begin{tabular}{|c|c|c|c|c|c|c|c|c|}
\hline & \multicolumn{4}{|c|}{ Version 1} & \multicolumn{4}{|c|}{ Version 2} \\
\hline & \multicolumn{2}{|c|}{ Unadjusted Estimates } & \multicolumn{2}{|c|}{ Adjusted Estimates } & \multicolumn{2}{|c|}{ Unadjusted Estimates } & \multicolumn{2}{|c|}{ Adjusted Estimates } \\
\hline & OR & $95 \% \mathrm{CI}$ & OR & $95 \% \mathrm{CI}$ & OR & $95 \% \mathrm{CI}$ & OR & $95 \% \mathrm{CI}$ \\
\hline \multicolumn{9}{|l|}{ Gender (ref*: Women) } \\
\hline Men & 0.95 & $(0.81,1.11)$ & 0.93 & $(0.78,1.01)$ & 1.01 & $(0.86,1.18)$ & 0.99 & $(0.84,1.18)$ \\
\hline Age & 1.02 & $(1.01,1.02)$ & 1.01 & $(1.01,1.02)$ & 1.01 & $(1.01,1.02)$ & 1.01 & $(1.00,1.01)$ \\
\hline \multicolumn{9}{|c|}{ Responsibility for Children (ref: Past) } \\
\hline Currently & 0.59 & $(0.48,0.73)$ & 0.89 & $(0.68,1.16)$ & 0.67 & $(0.55,0.83)$ & 0.83 & $(0.64,1.09)$ \\
\hline Never & 0.69 & $(0.57,0.84)$ & 0.91 & $(0.73,1.14)$ & 0.95 & $(0.78,1.15)$ & 1.09 & $(0.87,1.36)$ \\
\hline \multicolumn{9}{|c|}{ Highest Educational Qualification (ref: Other) } \\
\hline Degree or equivalent & 0.80 & $(0.66,0.98)$ & 0.86 & $(0.69,1.06)$ & 1.06 & $(0.87,1.28)$ & 1.02 & $(0.83,1.25)$ \\
\hline None & 1.29 & $(1.05,1.58)$ & 1.01 & $(0.81,1.28)$ & 1.19 & $(0.97,1.45)$ & 0.99 & $(0.79,1.25)$ \\
\hline \multicolumn{9}{|c|}{ Health Status (ref: Good) } \\
\hline Very good & 0.74 & $(0.61,0.89)$ & 0.84 & $(0.69,1.03)$ & 1.00 & $(0.84,1.20)$ & 1.05 & $(0.87,1.28)$ \\
\hline Fair, bad or very bad & 0.94 & $(0.77,1.15)$ & 0.84 & $(0.67,1.04)$ & 1.05 & $(0.86,1.28)$ & 0.95 & $(0.77,1.18)$ \\
\hline
\end{tabular}

*ref: represents reference group. Reference groups are those with highest frequency. 
these studies supports a conception of society as 'a fair system of co-operation over time, from one generation to another' (Rawls, 1996: 14).

For the questions we asked about health and environmental policies, standard economic approaches would accord Policy A (the policy favouring the current generation) the highest present value and deem it the most cost-effective. Take, for example, our question on health policies to save lives. To calculate the value of the different policy options, we use a constant 3.5 per cent discount rate and a value for saving a statistical life (expressed as the lost output and human costs of preventing a single fatality in the year 2010) of $\mathfrak{E} 1.632 \mathrm{~m}^{3}$ (Department for Transport, 2014). On this basis, the present value of Policy A is $\mathfrak{E} 3.77$ bn and Policy $\mathrm{B}$ is $\mathfrak{E} 1.37 \mathrm{bn}$. In version 1 of the question, where Policy $\mathrm{C}$ represents the equal shares option, its present value is $\mathfrak{L}_{2}$.9obn; in version 2, where benefits are more heavily weighted to future generations, its value falls to $\mathfrak{E} 2.02 \mathrm{bn}$. As this suggests, Policy A would therefore be seen to provide the greatest benefit to society.

However, in our study, Policy A was not the majority choice. When asked about health and environmental policies with effects that extend across three generations, only a minority selected the policy from which they would derive most benefit. Instead, the majority favoured policies where benefits were weighted to future generations. When asked about health policies, over 70 per cent opted for a policy where more lives were saved in their children's and grandchildren's generation than in their own, a proportion that rose to 80 per cent when an equal shares option was included. For environmental policies, over 60 per cent opted for a policy which favoured future generations (rising to 66 per cent when an equal shares option was included). As this suggests, a bias towards future generations was evident across two contrasting policy fields and outcomes: there was a high degree of support among the study participants for giving priority to the environments as well as the lives of the generations that follow them.

This bias was also not restricted to adults with children. While most of the sociological evidence on generational commitments comes from studies of parents and grandparents, a strong orientation to future generations was reported by non-parents in our study. With respect to protecting against flood damage, the adjusted analyses indicated that those who had never had parental responsibility for a child were not more likely to support the policy that maximised the benefits to their generation - and the large majority opted against this policy (74 per cent and 67 per cent respectively for version 1 and 2 of the question). With respect to saving lives, being a non-parent was an independent predictor of selecting the policy that most benefited their generation. However, again, the majority did not opt for this policy (87 per cent and 73 per cent respectively).

As noted earlier, our floods questions were asked during and following what was 'one, if not the most, exceptional periods of winter rainfall in at least 248 years' (Met Office, 2014: 2). The winter of 2014/15 saw extensive flooding in Britain, with a toll that included loss of life and damage to homes, businesses and transport 
links (Hartwell-Naguib and Roberts, 2014). Awareness of this human cost may have increased support for the policy from which their generation gained most (Policy A). Alternatively, it may have heightened concerns about the flood risks that may be faced by future generations. In a survey of public perceptions of flooding conducted during August-October 2014, a large majority ( 72 per cent) of respondents agreed with the statement that 'the floods showed us what we can expect in future from climate change' (Capstick et al., 2015: 30). As this example indicates, studies based on discrete choice questions such as ours need to be complemented by other evidence on people's time preferences and the experiences that shape them.

We also recognise that expressed preferences are sensitive to the elicitation method, including the framing of the question and sequencing of options (Frederick et al., 2002). We adapted a discrete choice question used in a US study (Frederick, 2003) and varied the ordering of policies across survey months to reduce potential response biases. In Frederick's study, participants were limited to two policy options: saving all the lives in 'your generation' or saving an equal number of lives in each of the three generations. We reduced possible framing effects by including benefits to future generations in the policy option (Policy A) that most benefited the current generation and by including two policy options that brought greater benefits to future generations. We also re-ran the questions replacing health policies that deliver human benefits with environmental policies bringing non-human benefits. Across all these variants of the question, only a minority opted for the policy that brought the greatest gain to their generation.

It is possible that the time preferences evident in our study are particular to health and environmental policies, with these two areas evoking a stronger orientation to future generations that other policy scenarios would have done. The UK population demonstrates a consistently high level of collective commitment to the National Health Service (and to state education) (Park et al., 2013). As in other European countries, the public also identifies climate change as their main environmental concern (European Commission: DG Environment, 2008). However, compared with health and education, broader infrastructure is viewed as a low priority for additional investment (along with social security benefits) (Park et al., 2013). It is therefore unlikely that the patterns in our survey are a simple artefact of the selected policy scenarios.

Most studies of preferences over long time horizons frame their questions around anonymous lives. In our study, the time-varying impacts of different policies were explicitly couched in generational terms and, further, in terms of generations to which respondents are likely to have felt a close affinity. The strong pro-future preferences may therefore reflect both personal ties to younger family members (including anticipated ties to those yet to be born) and a broader social ethic around safeguarding future generations. Wider research indicates that individuals have multiple sets of values and preferences, including those in line 
with an individual's sense of what is in their own self-interest and ones that express 'what is good, right, and desirable in a society' (Schwartz, 1999: 25). Our policy questions are likely to have tapped into both sets of values. It could therefore be argued that our study blurs the distinction between individual and social time preferences and between self-interest and societal interest, and these dimensions should be studied separately. However, we would counter that, for policies that impact on the welfare of future generations, the distinction between self-interest and societal interest dissolves. The future lives and environments of one's own kin are inextricably bound up with policies that promote the health and protect the environments of everyone's kin. This is particularly true of policies to mitigate the effects of environmental and climate change, where the time window for effective action is rapidly closing and today's policy choices will therefore determine both our individual futures and 'our common future' (UN, 1987).

The inter-dependency of individual and societal interest has been explored in economic studies of intergenerational altruism. Individuals are seen to display intergenerational altruism if they care about the wellbeing of the next generation and appreciate that the wellbeing of this future generation rests, in turn, on the wellbeing of the generation that will follow them. 'Pure' intergenerational altruists go further and appreciate that future generations may not share their altruistic sentiments (Millner, 2016). Economic analyses of intergenerational altruism have relied primarily on theoretical and model-based studies (Galperti and Strulovici, 2015; Saez-Marti and Weibull, 2005). Our study points to the need for empirical studies of the values underlying people's attitudes to future generations, including their willingness to make material sacrifices to ensure a better world for generations to which they are not related.

\section{Conclusion}

How to represent the interests of future generations in policy decision-making has long been recognised as a central challenge of policy evaluation. The accelerating pace of environmental and climate change is adding urgency to this issue (Steffen et al., 2011; Stern, 2006).

Our study of adults in Britain raises questions about a core assumption underpinning standard policy evaluation: that people prefer policies that most benefit their generation. The study points, instead, to a strong preference for policies bringing greater benefit to the generations that follow. These findings accord with sociological evidence that concern for future generations is among the values that many people hold in common.

An appeal to common values has been identified as important in securing public support for policies to address 'bigger-than-self' challenges like improving health and tackling environmental and climate change (Crompton, 2010). Such an appeal underpins a series of landmark reports on environmental and climate 
change, including the Brundtland Commission (UN, 1987), the Stern Report (2006) and the Lancet Commission on planetary health (Whitmee et al., 2015). Presenting policy challenges in ways that connect with positive emotions, like hope, care, compassion and pride, is seen to help activate public engagement (Markowitz and Shariff, 2012). Again, a commitment to future generations does this: it is a commitment anchored in these emotions. Understanding more about this commitment could help community organisations and governments build public support for future-oriented policies explicitly designed to protect the lives and environments of future generations.

\section{Acknowledgments}

The study forms part of the Health of Populations and Ecosystems (HOPE) project funded by the Economic and Social Research Council (ES/Loo3015/1). We thank the HOPE advisory groups for their contribution to the study and the feedback on our paper from the Journal's reviewers. The views expressed are those of the authors and not necessarily those of the ESRC.

\section{Notes}

1 The setting of a $2^{\circ} \mathrm{C}$ increase in global temperatures as the threshold between 'safe' and 'dangerous' climate change is recognised to be a political process; there is accumulating evidence that the increase to date is already endangering lives and livelihoods (Watts et al., 2015; Whitmee et al., 2015).

2 The question ran for two months only as a check on the version 1 findings and to enable subsequent months to move onto questions on flood protection.

3 UK Department for Transport guidance sets a value of $\mathfrak{1} 1,070,596$, in 2010 prices, on the human costs of a single fatality, representing the 'pure' willingness-to-pay based value of safety to individuals themselves. A further $\mathfrak{E}_{561,332}$ is added to allow for lost output to the economy, and $\mathfrak{E}_{964}$ in medical and ambulance costs, to arrive at a total figure of $\mathfrak{E} 1,632,892$ for preventing a single fatality. Different values multiply all the absolute monetary amounts by a constant; they therefore keep the same ranking of the options and the same ratio of values between any two options.

\section{References}

Adams, B. and Groves, C. (2007), Future Matters: Action. Knowledge, Ethics. Leiden and Boston: Brill.

Arber, S. and Timonen, V. (eds). (2012), Contemporary Grandparenting: Changing Family Relationships in Global Contexts. Bristol: Policy Press.

Bengtson, V.L. (2001), Beyond the nuclear family: the increasing importance of multigenerational bonds. Journal of Marriage and Family, 63(1), 1-16.

Cairns, J. and van der Pol, M. (2000), The estimation of marginal time preference in a UK-wide sample (TEMPUS) project: a review, Health Technology Assessment, 4: 1, 83.

Capstick, S.B., Demski, C.C., Sposato, R.G., Pidgeon, N.F., Spence, A. and Corner, A. (2015), Public perceptions of climate change in Britain following the winter 2013/14 flooding, Understanding Risk Research Group Working Paper 15-01, Cardiff University. http://c3wales. org/wp-content/uploads/2015/o1/URG-15-01-Flood-Climate-report-final2.pdf

Broome, J. (1994), Discounting the future. Philosophy \& Public Affairs, 23(2), 128-56.

Chapman, G. B. (2001), Time preferences for the very long term. Acta psychologica, 108(2), 95-116. 
Crompton, T. (2010), Common Values: the Case for Working with our Cultural Values, WWF-UK, https://www.foe.co.uk/sites/default/files/downloads/common_cause_report.pdf

Cropper, M. L., Aydede, S. K. and Portney, P. R. (1994), Preferences for life saving programs: how the public discounts time and age. Journal of Risk and Uncertainty, 8(3), 243265.

Department for Transport. (2014), WebTAG: Transport Analysis Guidance Data Book, May 2014, Table A 4.1.1. https://www.gov.uk/government/publications/webtag-tagdata-book-may-2014

European Commission: DG Environment. (2008), Special Eurobarometer 295: Attitudes of European citizens towards the environment. http://ec.europa.eu/ public_opinion/archives/ebs/ebs_295_en.pdf

Frederick, S. (2003), Measuring intergenerational time preference: Are future lives valued less? Journal of Risk and Uncertainty, 26(1), 39-53.

Frederick, S., Loewenstein, G. and O'Donoghue, T. (2002), Time discounting and time preference: A critical review, Journal of Economic Literature, 40, 351-401.

Galperti, S. and Strulovici, B. (2015), A Theory of Intergenerational Altruism. http://faculty. wcas.northwestern.edu/ bhs675/TIC.pdf

Giddens, A. (1991), Modernity and Self-Identity, Oxford: Policy Press.

HM Treasury (2013), The Green Book: appraisal and evaluation in Central Government. London: the Stationery Office. https://www.gov.uk/government/publications/the-greenbook-appraisal-and-evaluation-in-central-governent

Hartwell-Naguib, S. and Roberts, N. (2014), Winter Floods 2013/14, SN/SC/06809. London: House of Commons Library.

Hawkes, W. and Joshi, H. (2007), Grandparents. Millennium Cohort Study Briefing, 4.

Hosmer, D. W., Lemeshow, S. and Rodney, X. Sturdivant, R.X. (2013), Applied Logistic Regression, 3rd Edition. Chichester: Wiley.

Intergovernmental Panel on Climate Change (IPCC). (2014), Climate Change 2014: Impacts, Adaptation, and Vulnerability. Part A: Global and Sectoral Aspects. Contribution of Working Group II to the Fifth Assessment Report of the Intergovernmental Panel on Climate Change Field, C. B., Barros, V. R., Dokken, D. J., Mach, K. J., Mastrandrea, M. D., Bilir, T. E., Chatterjee, M., Ebi, K. L., Estrada, Y. O., Genova, R. C., Girma, B., Kissel, E. S., Levy, A. N., MacCracken, S., Mastrandrea, P. R., and White, L. L. (Eds.), http://ipcc-wg2.gov/AR5/ images/uploads/WG2AR5_SPM_FINAL.pdf

Johannesson, M. and Johansson, P. O. (1996), The discounting of lives saved in future generations-some empirical results. Health Economics, 5(4), 329-332.

Kymlicka, W. (2002), Contemporary Political Philosophy: An introduction: Oxford University Press.

Lawless, L., Drichoutis, A.C. and Nayga, R.M. (2013), 'Time preferences and health behaviour: a review', Agricultural and Food Economics, 1, 17, doi: 10.1186/2193-7532-1-17.

Leopold, T. and Skopek, J. (2015), 'The demography of grandparenthood: an international profile', Social Forces, 94: 2, 801-832.

Levell, P., Roantree, B. and Shaw, J. (2015), Redistribution from a lifetime perspective. London: Institute for Fiscal Studies.

Markowitz, E.M. and Shariff, A.F. (2012), 'Climate change and moral judgement', Nature Climate Change, 2, 243-247.

Met Office. (2014), The Recent Storms and Floods in the UK, Met Office/Centre for Ecology and Hydrology. www.metoffice.gov.uk/media/pdf/n/i/Recent_Storms_ Briefing_Final_07023.pdf

Morgan, D. H. J. (1996), Family connections, Cambridge, England: Polity Press.

Millner, A. (2016), Heterogeneous intergenerational altruism, Working Paper No. 226, London: Grantham Institute on Climate Change and the Environment http://www.cccep.ac.uk/ wp-content/uploads/2016/o2/Working-Paper-226-Millner.pdf

Myers, S. and Patz, J. A. (2009), Emerging threats to human health from global environmental change. Annual Review of Environment and Resources, 34, 223-252. 
New, M., Liverman, D., Schroder, H. and Anderson, K. (2011), Four degrees and beyond: the potential for a global temperature increase of four degrees and its implications. Phil. Trans. R. Soc. A, 369, 6-19. doi:doi:10.1098/rsta.2010.0303

Office for Economic Co-operation and Development (OECD). (2011), Doing Better for Families. Paris: OECD http://www.oecd.org/social/soc/doingbetterforfamilies.htm

Office for National Statistics (ONS) (2013), Live Births in England and Wales by Characteristics of Mother 1, 2012, Fareham, Hampshire: ONS.

Office for National Statistics (ONS) (2014), Opinions and Lifestyle (Opinions) Survey Information Guide 2013-14. http://www.ons.gov.uk/ons/about-ons/productsand-services/opn/index.html.

Oliver, A. (2013), A normative perspective on discounting health outcomes. Journal of Health Services Research \& Policy, 18(3), 186-189.

Park, A., Bryson, C., Clery, E., Curtice, J. and Phillips, M. (Eds.). (2013), British Social Attitudes: the 3oth report. London: NatCen Social Research.

Pretty, J. (2013), The consumption of a finite planet: well-being, convergence, divergence and the nascent green economy. Environmental and Resource Economics, 55(4), 475-499. doi:10.1007/s10640-013-9680-9

Rawls, J. (1996), Political Liberalism, New York: Columbia University Press.

Rockström, J., Steffen, W., Noone, K., Persson, Å., Chapin, F. S., Lambin, E. F.,. . . Foley, J. A. (2009), A safe operating space for humanity. Nature, 461(7263), 472-475.

Saez-Marti, M. and Weibull, J.W. (2005), Discounting and altruism to future decisionmakers. Journal of Economic Theory, 122(2), 254-266.

Schwartz, S.H. (1999), A theory of cultural values and some implications for work, Applied Psychology: an International Review, 48:1, 23-47.

Silverstein, M., Giarrusso, R. and Bengtson, V. L. (1998), Intergenerational solidarity and the grandparent role. In: Szinovacz, M. E. (Ed.), Handbook on grandparenthood, 144-158. Westport, CT, USA: Greenwood Press.

StataCorp (2013), Stata Statistical Software: Release 13: College Station, TX: StataCorp LP.

Steffen, W., Persson, Å., Deutsch, L., Zalasiewicz, J., Williams, M., Richardson, K.,. . . Gordon, L. (2011), The Anthropocene: from global change to planetary stewardship. Ambio, 40(7), $739-761$.

Steffen, W., Sanderson, R. A., Tyson, P. D., Jäger, J., Matson, P. A., Moore III, B. and Turner, B. L. (2006), Global change and the earth system: a planet under pressure: Springer.

Stern, N., Peters, S., Bakhshien, V., Bowen, A., Cameron, C., Catovsky, S. and Crane, D. (2006), Stern Review: The Economics of Climate Change. London: HM Treasury.

Thompson, D. F. (2010), Representing future generations: political presentism and democratic trusteeship. Critical Review of International Social and Political Philosophy, 13(1), $17-37$.

UK Statistics Authority (2009), Code of Practice for Official Statistics, Version 1.o, London: UK Statistics Authority. http://webarchive.nationalarchives.gov.uk/ 20160105160709/http://statisticsauthority.gov.uk/assessment/code-of-practice/index.html.

US Census Bureau (2015), Historical Table 1. Percent Childless and Births per 1,00o women in the last 12 months, 1976-2014. US Census Bureau. http://www.census.gov/ hhes/fertility/data/cps/historical.html

United Nations (UN) World Commission on Environment and Development. (1987), Our Common Future, Report of the World Commission on Environment and Development (Bruntland Commission). Oxford: Oxford University Press.

Watts, N., Adger, W. N., Agnolucci, P., Blackstock, J., Byass, P., Cai, W.,. . Costello, A. (2015), Health and climate change: policy responses to protect public health. The Lancet, 386(10006), 1861-1914. doi:10.1016/So140-6736(15)60854-6

Whitmee, S., Haines, A., Beyrer, C., Boltz, F., Capon, A. G., de Souza, Dias, B. F., . . Yach, D. (2015), Safeguarding human health in the Anthropocene epoch: report of The Rockefeller 
Foundation-Lancet Commission on planetary health. The Lancet, 386(10007), 1973-2028. doi:10.1016/So140-6736(15)60901-1

World Meteorological Organization (WMO) (2016), The Global Climate in 2011-15, WMO-No. 1179, Geneva: World Meteorological Organization

World Health Organisation (WHO) (2015), Global Health Observatory (GHO) data. http://www.who.int/gho/mortality_burden_disease/life_tables/en/ 